\title{
Correction to: Patient-specific SPECT imaging protocols to standardize image noise
}

\author{
Sarah G. Cuddy-Walsh, PhD, ${ }^{\mathrm{a}, \mathrm{b}}$ Duncan C. Clackdoyle, ${ }^{\mathrm{b}}$ \\ Jennifer M. Renaud, MSc, ${ }^{b}$ and R. Glenn Wells, PhD ${ }^{a, b}$ \\ a Department of Physics, Carleton University, Ottawa, ON, Canada \\ b Division of Cardiology, Cardiac Imaging, University of Ottawa Heart Institute, Ottawa, ON, \\ Canada
}

doi: $10.1007 / \mathrm{s} 12350-019-01685-0$

\section{CORRECTION TO: JOURNAL OF NUCLEAR CARDIOLOGY ${ }^{\circledR}$ HTTPS://DOI.ORG/10.1007/S12350-019-01664-5}

The originally published version of this article contained typographical errors in the units of photon sensitivity. The units of counts $\cdot \mathrm{MBq}^{-1} \cdot \mathrm{min}^{-1}$ and kcounts $\cdot \mathrm{mCi}^{-1} \cdot \min ^{-1}$ were mistakenly recorded as counts $\cdot \mathrm{MBq} \cdot \min$ and $\mathrm{kcounts} \cdot \mathrm{mCi} \cdot \min$ respectively. The original article has been corrected.

Publisher's Note Springer Nature remains neutral with regard to jurisdictional claims in published maps and institutional affiliations.
The original article can be found online at https://doi.org/10.1007/ s12350-019-01664-5.

Reprint requests: Sarah G. Cuddy-Walsh, PhD, Division of Cardiology, Cardiac Imaging, University of Ottawa Heart Institute, H2258 - 40 Ruskin Street, Ottawa, Ontario, K1Y 4W7, Canada; swalsh@ottawaheart.ca

J Nucl Cardiol 2020;27:1382.

$1071-3581 / \$ 34.00$

Copyright (c) 2019 American Society of Nuclear Cardiology. 